\title{
The Cell Research Trends of Asthma: A Stem Frequency Analysis of the Literature
}

\author{
Wenchao Tang $\left(\mathbb{D},{ }^{1}\right.$ Yi Shang $\left(\mathbb{D},{ }^{2}\right.$ Bin Xiao ${ }^{(D)},{ }^{1}$ Peitong Wen $\left(\mathbb{D},{ }^{1}\right.$ Ruoyun Lyu $(\mathbb{D}){ }^{1}$ \\ and Ke Ning $\mathbb{D}^{3}$ \\ ${ }^{1}$ School of Acupuncture-Moxibustion and Tuina, Shanghai University of Traditional Chinese Medicine, Shanghai 201203, China \\ ${ }^{2}$ Department of Electrical Engineering and Computer Science, University of Missouri, Columbia, MO 65211, USA \\ ${ }^{3}$ School of Basic Medical Sciences, Shanghai University of Traditional Chinese Medicine, Shanghai 201203, China
}

Correspondence should be addressed to Wenchao Tang; vincent.tang@shutcm.edu.cn

Received 15 November 2017; Revised 26 March 2018; Accepted 22 July 2018; Published 23 August 2018

Academic Editor: Weidong Cai

Copyright (c) 2018 Wenchao Tang et al. This is an open access article distributed under the Creative Commons Attribution License, which permits unrestricted use, distribution, and reproduction in any medium, provided the original work is properly cited.

\begin{abstract}
Objective. This study summarized asthma literature indexed in the Medical Literature Analysis and Retrieval System Online (MEDLINE) and explored the history and present trends of asthma cell research by stem frequency ranking to forecast the prospect of future work. Methods. Literature was obtained from MEDLINE for the past 30 years and divided into three groups by decade as the retrieval time. The frequency of stemmed words in each group was calculated using Python with Apache Spark and the Natural Language Tool Kit for ranking. The unique stems or shared stems of 3 decades were summarized. Results. A total of 1331,4393 , and 7215 records were retrieved from 3 decades chronologically, and the stem ranking of the top 50 were listed by frequency. The number of stems shared with 3 decades was 26 and with the first and last 2 decades was 5 and 13. Conclusions. The number of cell research studies of asthma has increased rapidly, and scholars have paid more attentions on experimental research, especially on mechanistic research. Eosinophils, mast cells, and T cells are the hot spots of immunocyte research, while epithelia and smooth muscle cells are the hot spots of structural cell research. The research trend is closely linked with the development of experimental technology, including animal models. Early studies featured basic research, but immunity research has dominated in recent decades. The distinct definition of asthma phenotypes associated with genetic characteristics, immunity research, and the introduction of new cells will be the hot spots in future work.
\end{abstract}

\section{Introduction}

Asthma is a major public health problem around the world, affecting individuals across the age spectrum from infants to older adults. Therefore, research on its pathogenesis and treatment has been a hot topic in the study of respiratory diseases. It is now well accepted that cell activity has a close relationship with pathogenesis of asthma, and numerous basic and clinical studies focus on different types of relevant cells.

As a typical example of type I hypersensitivity, the research of immune cells concerned with asthma, such as lymphocytes, monocytes, and mast cells, is most common. For instance, Tcell subsets include $\mathrm{CD}^{+}, \mathrm{CD}^{+}$T cells [1], Th2, Th17 [2], Th9 [3], and so on. Except for immune-relevant cells, structural cells of the airways, such as epithelial cells [4], smooth muscle cells [5], and bronchial myofibroblasts [6], are also an important focus of research. In recent years, cell therapy has attracted the attention of researchers to treat asthma and its complications. A study revealed that bone marrow-derived mesenchymal stem cell (BMSC) therapy significantly suppressed lung pathology and inflammation in the ovalbumin-induced asthma mouse model [7].

Currently, there has been continued interest in targeting airway cells for developing new asthma treatments. Therefore, it has become imperative to analyze the current trend and future direction of asthma cell research. This study summarized asthma literature indexed in the Medical Literature Analysis and Retrieval System Online (MEDLINE) 
of the National Library of Medicine (NLM) in the past 30 years and explored the history and present state of asthma cell research by stem frequency rank to provide ideas for future work.

\section{Objects and Methods}

2.1. Objects. Literature of asthma cell research indexed from MEDLINE in the past 30 years was divided into three groups with 10 years as the retrieval time. The literature containing the keywords "Asthma" and "Cell" in the fields "Title" or "Abstract" was included for further investigation. The limit of publication date in the three groups were "January 1, 1987, to December 31, 1996," "January 1, 1997, to December 13, 2006," and "January 1, 2007, to December 31, 2016," respectively.

The search results of each decade were exported into a CSV file with information such as title and author. All the titles of each CSV file were saved as a text file for analysis with stem frequency rank.

2.2. Programming. Due to the large amount data in the literature, we adopted Apache Hadoop, which is commonly used in big data analysis as the data storage framework. As a file system supporting a data-intensive distributed application, Apache Hadoop has better distribution characteristics and provides file services with both reliability and mobility for the program development [8]. To speed up the computation, we selected the Apache Spark open-source computing framework in our study instead of the Apache Hadoop built-in MapReduce computing method. The major difference between Spark and MapReduce lies in in-memory computing technology, which means the data are analyzed and processed to acquire the results in the memory before being written to the hard disk [9].

The analysis of stem frequency ranking was handled using the Natural Language Tool Kit (NLTK). NLTK is an important tool for dealing with human natural language, which can be applied to word merging, text retrieval, and statistics, and so on. The technologies such as "Word frequency Accumulation," "Stemming Processing," and "Stopword Filtering" applied in this study were all performed with NLTK [10]. According to the integrated application of the above techniques, the programming environment and working process can be summarized as follows:

(1) Programming environment: EC2 server of Amazon Web Services (AWS) platform was selected as the programming environment.

Server model: $\mathrm{t} 2$ micro

Server Location: Oregon, United States

Operating System and software: Ubuntu Server 14.04 with built-in Python language (version 2.7.3), Apache Spark (version 1.6.2), and NLTK (version 3.0).

(2) Working process:

(a) Import a text file.

(b) Create the Spark context. (c) Convert all text to lowercase.

(d) Remove punctuations, empty lines, and nonletter symbols.

(e) Use stop word list to filter irrelevant vocabulary of research such as "they," "where," "to," and "is." The words influencing the results such as "review," "asthma," and "cell" were also added into the stop word list for filtering.

(f) Stemming for reducing each word to its base form by removing its common morphological ending. In this study, we utilized PorterStemmer, a Python wrapper of the libstemmer library, to perform the stemming step.

(g) Rank all stems according to their frequency.

(h) List the top 50 stems, and output the results.

\section{Results}

3.1. The Number of Studies Retrieved by Searching Three Decades. 1331, 4393, and 7215 records were retrieved in the 1st, $2 \mathrm{nd}$, and 3 rd decade, respectively, which shows that the number of cell research literature of asthma indexed by MEDLINE presents explosive growth from 1987 to 2017; the literature number of the next decade was 1.5-2 times greater than the previous one.

3.2. The Top 50 Stems of Three Decades. The top 50 stems of 3 decades are listed in Table 1 . The number of stems shared with 3 decades was 26 (Figure 1) and with the first and last 2 decades were 5 and 13 (Figures 2 and 3). The numbers of unique stems of 3 decades were 19,6 , and 11 , respectively (Figure 4). According to the chronological order, the author names with the highest frequency of the three decades are Pascal Chanez (Aix-Marseille University, Paris, France), Stephen T. Holgate (University of Southampton, Southampton, United Kingdom), and Andrew Halayko (University of Manitoba, Manitoba, Canada).

\section{Discussion}

4.1. Mainstream Research Trends in Three Decades. The mainstream research trends can be summarized from stems shared with 3 decades. First, experimental research attracted more attention by researchers rather than clinical research. "Children" is the only relevant stem on behalf of clinical research for its frequent occurrence of asthma among children, and a study reported that asthma is common in children and is a leading cause of childhood hospitalization [11]. The stems related with experimental research, such as "respons," "express," and "induc," were much more common with rising frequency year after year. Mechanism (mechan) and interventional effect were the two main directions of experimental research, but mechanism was more popular among scholars because stems about activation (activ) of cells or pathways [12-14], immune or cell response (respons) [15-17], genetic or protein expression (express) [18-20], and the role of cells or relevant genes or protein were always in the top 10 among all decades. The other 3 stems about mechanism research "product," "induc," and 
TABLE 1: Top 50 stems of three decades.

\begin{tabular}{|c|c|c|c|c|c|c|}
\hline \multirow{2}{*}{ Ranking } & \multicolumn{2}{|c|}{ 1st decade } & \multicolumn{2}{|c|}{ 2nd decade } & \multicolumn{2}{|c|}{ 3rd decade } \\
\hline & Stem & Frequency & Stem & Frequency & Stem & Frequency \\
\hline 1 & eosinophil & 147 & inflamm & 545 & inflamm & 1153 \\
\hline 2 & activ & 115 & express & 425 & respons & 552 \\
\hline 3 & respons & 113 & eosinophil & 358 & express & 537 \\
\hline 4 & inflamm & 102 & receptor & 351 & $\mathrm{t}$ & 526 \\
\hline 5 & $\mathrm{t}$ & 90 & activ & 341 & activ & 525 \\
\hline 6 & express & 84 & respons & 339 & receptor & 508 \\
\hline 7 & bronchoalveolar & 80 & $\mathrm{t}$ & 326 & mice & 476 \\
\hline 8 & role & 76 & role & 321 & role & 429 \\
\hline 9 & lavag & 75 & induc & 298 & epitheli & 422 \\
\hline 10 & mast & 72 & mast & 232 & induc & 410 \\
\hline 11 & lymphocyt & 71 & smooth & 229 & muscl & 406 \\
\hline 12 & atop & 67 & muscl & 228 & smooth & 401 \\
\hline 13 & cytokin & 61 & epitheli & 228 & inhibit & 401 \\
\hline 14 & receptor & 60 & cytokin & 211 & immun & 336 \\
\hline 15 & releas & 59 & product & 207 & mous & 333 \\
\hline 16 & induc & 58 & inhibit & 205 & murin & 330 \\
\hline 17 & inhibit & 55 & allergen & 200 & mast & 328 \\
\hline 18 & allergen & 54 & atop & 177 & eosinophil & 294 \\
\hline 19 & product & 53 & protein & 171 & remodel & 290 \\
\hline 20 & epitheli & 53 & sputum & 168 & signal & 257 \\
\hline 21 & inhal & 50 & gene & 166 & protein & 250 \\
\hline 22 & adhes & 49 & murin & 160 & children & 245 \\
\hline 23 & mediat & 47 & mice & 158 & cytokin & 244 \\
\hline 24 & inflammatori & 46 & pulmonari & 148 & inflammatori & 235 \\
\hline 25 & children & 45 & inflammatori & 146 & suppress & 234 \\
\hline 26 & histamin & 43 & hyperrespons & 144 & hyperrespons & 232 \\
\hline 27 & muscl & 41 & children & 136 & pulmonari & 230 \\
\hline 28 & leukotrien & 40 & inhal & 136 & gene & 226 \\
\hline 29 & antigen & 40 & th2 & 118 & product & 224 \\
\hline 30 & smooth & 40 & remodel & 118 & th2 & 215 \\
\hline 31 & fluid & 38 & inhibitor & 118 & modul & 213 \\
\hline 32 & sodium & 38 & mechan & 116 & dendrit & 210 \\
\hline 33 & ige & 37 & develop & 116 & develop & 207 \\
\hline 34 & peripher & 34 & rat & 115 & allergen & 196 \\
\hline 35 & macrophag & 34 & allergeninduc & 114 & attenu & 195 \\
\hline 36 & pulmonari & 33 & immun & 113 & pathway & 190 \\
\hline 37 & vitro & 32 & lymphocyt & 110 & differenti & 190 \\
\hline 38 & mechan & 32 & infect & 106 & target & 185 \\
\hline 39 & select & 31 & sensit & 102 & novel & 183 \\
\hline 40 & protein & 30 & novel & 102 & infect & 177 \\
\hline 41 & therapi & 28 & mediat & 100 & mediat & 176 \\
\hline 42 & glucocorticoid & 28 & peripher & 100 & regulatori & 174 \\
\hline 43 & bronchoconstrict & 28 & signal & 100 & type & 164 \\
\hline 44 & guinea & 28 & leukotrien & 98 & sever & 164 \\
\hline 45 & chang & 28 & allergi & 97 & rat & 164 \\
\hline 46 & pig & 28 & growth & 97 & promot & 161 \\
\hline 47 & tcell & 27 & chemokin & 96 & inhibitor & 156 \\
\hline 48 & hyperrespons & 27 & modul & 93 & allergi & 156 \\
\hline 49 & immun & 27 & mous & 93 & mechan & 151 \\
\hline 50 & modul & 27 & kinas & 93 & potenti & 150 \\
\hline
\end{tabular}

"mediat" were mainly frequent in "production of cytokines" [21], "protein or allergen-induced" [22], and "cell-mediated" [23], respectively. Inhibition was a typical intervention effect and its stem "inhibit" was ranked in our results. For example, the following were included: the inhibition of glucocorticoids on degranulation of mast cells in allergic asthma [24], inhibition of the kinase ITK in a mouse model of asthma reduces cell death [25], and the inhibition of CD38 gene- modified dendritic cells on murine asthma development [26].

Second, two frequent stems about pathologic changes of asthma were "inflamm" and "hyperrespons." "Inflamm" was also in the top 10 because airway inflammation is the main expression of asthma, with mechanism research about inflammation such as etiological agents and influence factor $[27,28]$, being very common. Hyperresponsiveness was 


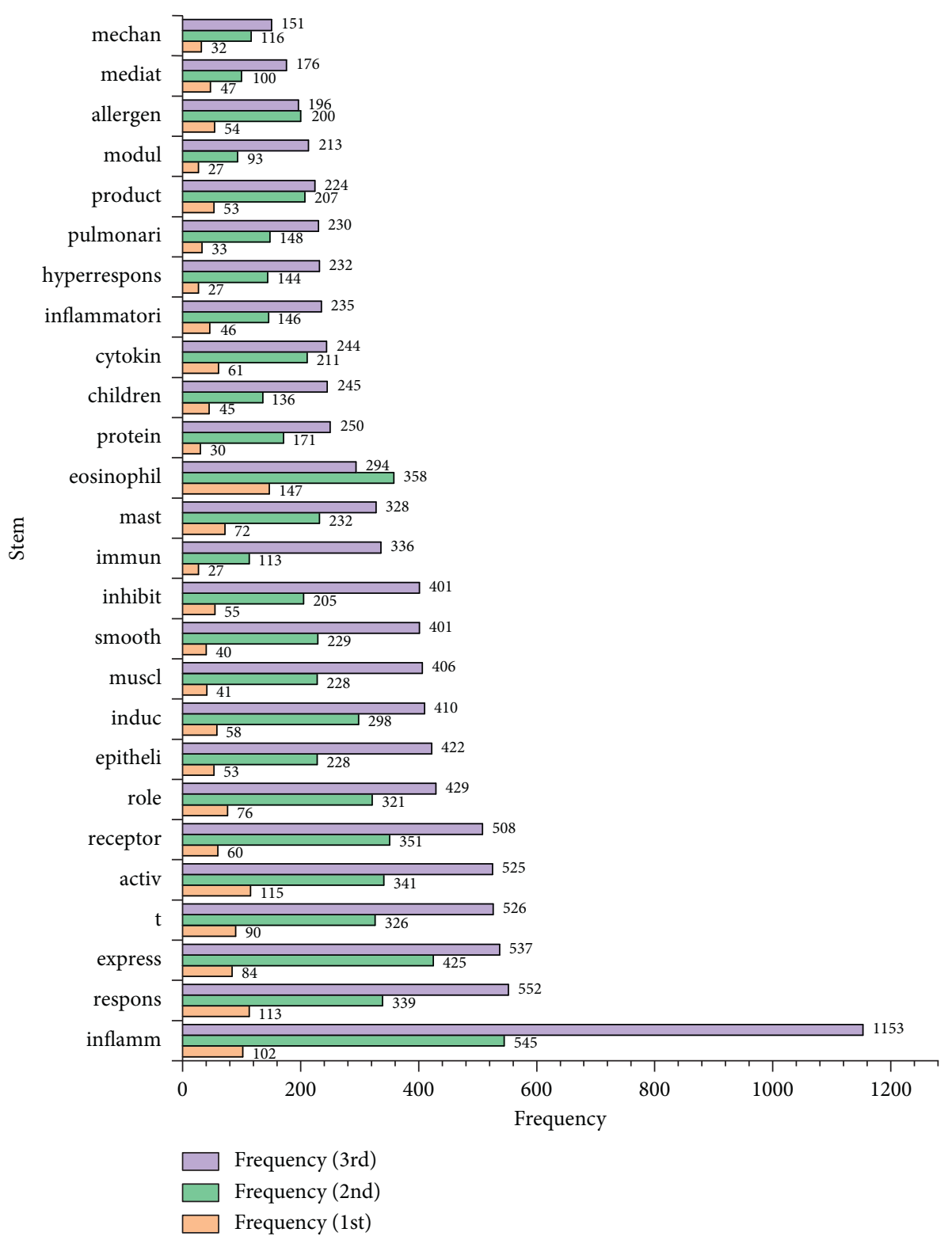

Figure 1: The shared stems of three decades. The orange, green, and purple bars show the frequencies of stems in the 1st, 2nd, and 3rd decade, respectively.

often mentioned with inflammation $[29,30]$ for immunologyrelated study of asthma.

Third, in terms of different types of cells related with asthma, eosinophils, mast cells, and T cells are the hot spots of immunocytes, according to the results of ranking. Mast cells are the "first line of defense" in which innate/adaptive immune cells can be activated to release a wide range of mediators by allergen-IgE-specific triggers and are widely distributed in tissues of the airway exposed to the environment, so mast cells preempt the critical roles played by histamine and mucus secretion in causing airway obstruction $[31,32]$. The studies about the expression of CD antigens [33-35] involving mast cells and its mediated cytokines [36] are very common. Airway eosinophilias are associated with the inflammatory response and likely participate in airway remodeling [37-40]. Many studies have reported that the expression of its granular proteins has functions relevant to the features of asthma, including histopathologic changes, reversible airway narrowing, and bronchial hyperreactivity [41-44]. The activated Tcells in the airway wall are associated with inflammation of asthma $[45,46]$, and the subsets of $\mathrm{T}$ cell antigens have attracted extensive attention by researchers, such as the T cells of CD4 $+(\mathrm{T}$ helper $)$ [47-51], CD8+ [52-54], CD25+ [55], CD28 $[56,57], \mathrm{CD} 29[58,59], \mathrm{CD} 39+$, and CD73 [60-63]. The imbalance of different subsets and the regulatory mechanism are the research emphasis of this field [64-67].

Epithelia and smooth muscle cells (SMCs) are the hot spots of structural cell studies. Research has shown that airway epithelial barrier dysfunction may have important implications for asthma [68-72]. The relevant genes or protein expression of epithelia and the regulatory 


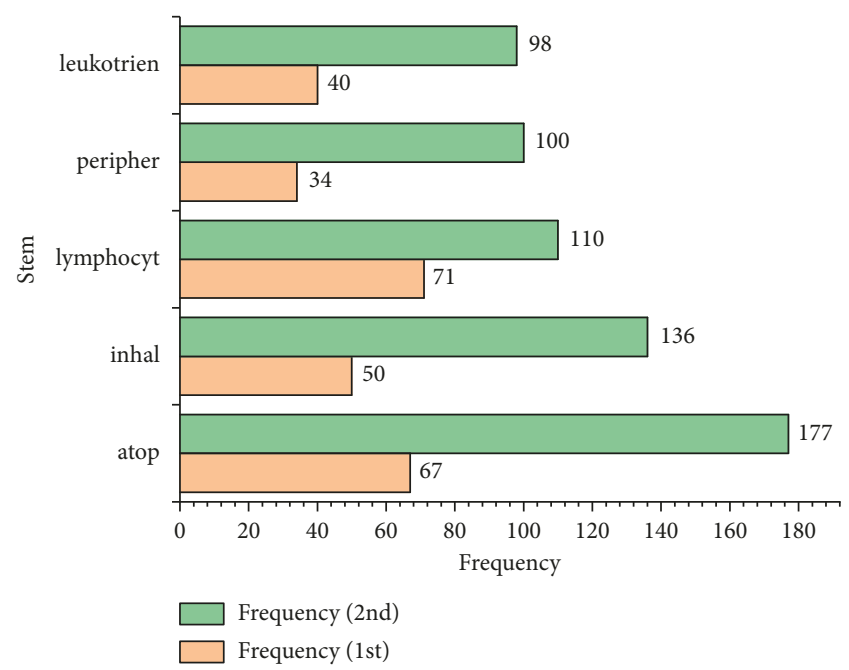

Figure 2: The shared stems of the first two decades. The orange and green bars show the frequencies of stems in the 1st and 2nd decade, respectively.

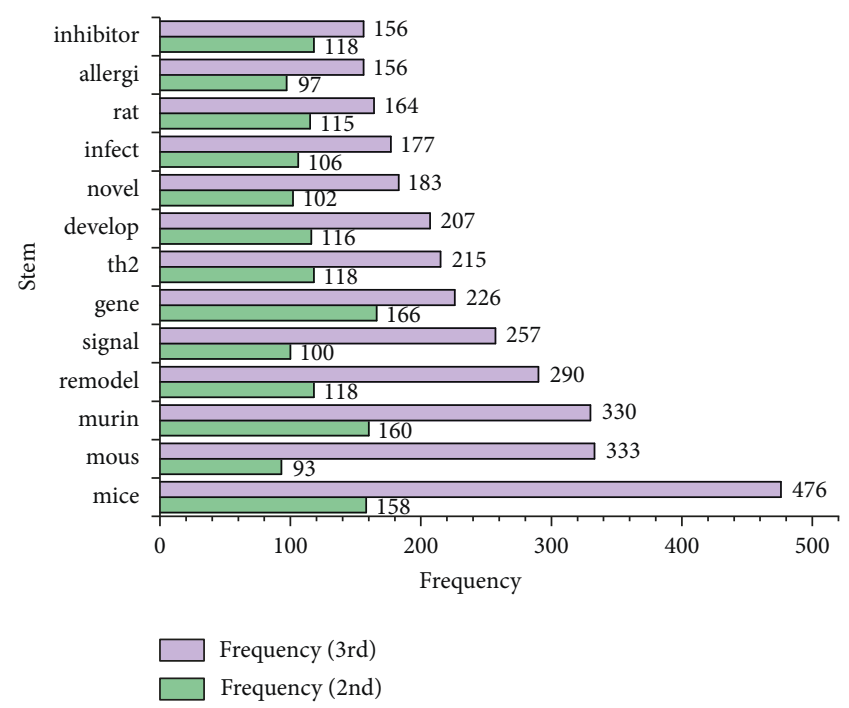

Figure 3: The shared stems of the last two decades. The green and purple bars show the frequencies of stems in the 2nd and 3rd decade, respectively.

mechanism of barrier function or dysfunction are the research emphasis $[27,28]$. It has been reported that SMCs isolated from asthma patients release more proinflammatory mediators than that in control subjects [73], which may contribute to airway wall remodeling [74].

4.2. Variation Trends of Research over Time. Several variation trends can be summarized after comparing the shared stems in the first and last two decades.

First, the phenotype definition of asthma has become gradually clearer. The shared stem "atopic" in the first two decades showed that "atopic" and "non-atopic" stems were often used to define the phenotypes of asthma due to the limited available data about asthma and atopy at that time [75], which resulted in ambiguity of the phenotype definition. However, the stem "allergi" shared with the last two decades indicated that the concept "allergic asthma" was widely used in studies [76,77], which indicates that the phenotype of asthma was definitive.

Second, genetic studies and airway remodeling have received more attention. Along with novel experiment technologies applied in molding and detection, more studies of signaling pathways [23] and airway remodeling [78] at the gene level [18] were performed in the last 2 decades with evidence from the common stems "gene," "signal," and "remodel." Moreover, the shared stems "mice," "rat," "murine," and "mous" in the last two decades have shown that more animal models of rats were used in such experimental research [79-82]. In contrast, the shared stems of the first two decades implied studies of downstream signaling pathways including cytokines [83], leukotrienes [84], peripheral blood [85], or different types of receptors [86] attracted great attention at that time.

Finally, looking into changes in therapeutic approaches, the shared stem "inhal" in first two decades showed that inhaled treatment was mainstream at the early stage $[87,88]$. However, it ceased to be the hot spot because of the continuous exploration of new treatments or drugs, such as Montelukast [89] and monoclonal antibodies [90]. During the past 20 years, the shared stem, "inhibitor," indicated that as one type of a new drug for asthma, inhibitors such as histone deacetylase inhibitors [91, 92] and tyrosine kinase inhibitors [93] were implicated in influencing gene expression of asthma-related cytokines [94], gaining importance.

4.3. Distinctive Research Hot Spots of Every Decade. Several distinctive research hot spots can be analyzed according to the unique stems of each decade. Two specific aspects were concerned in the studies of the first decade. First, the relevant mechanism researches including the release of cytokines [95] or histamines [95] and cell adhesion [96] about bronchoalveolar and macrophages [97, 98] were performed with corresponding experimental approaches such as cell counting method, immunofluorescence, ELISA, and bioassay commonly [99]. Second, there was specific phenomenon that researchers were enthusiastic about asthma therapy, and glucocorticoid [100] and nedocromil sodium [101] were often studied using pulmonary function test.

The main hot spot drawn from the unique stems of the second decade is that the allergen-induced topics, such as airway hyperresponsiveness [102] or inflammation and the regulation mechanism of allergic sensitization [103], were popular. Its relevant common experimental techniques included immunohistochemistry, flow cytometry, RT-PCR, and ELISA [104]. In addition, the specific research topics "different types of growth factors" [105], "kinases" [106], and "chemokines" [107] were also common due to their relevant roles that have been gradually explored and affirmed.

With the development of genetic technology, the research of the immune response became prevalent in the third decade, and specific stems about its mechanism, regulation, and signaling pathways such as "pathway" [108], 


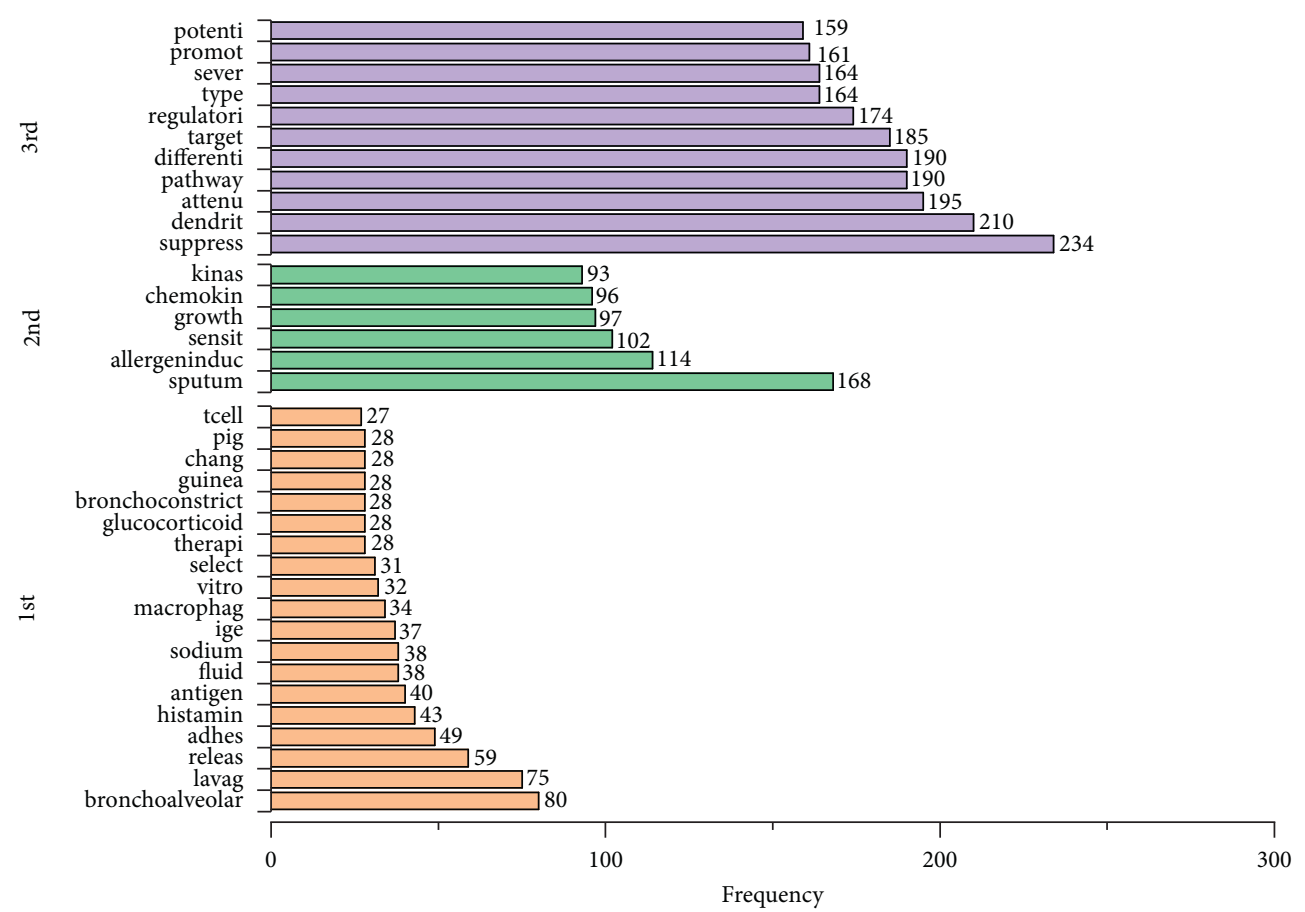

Figure 4: The unique stems of three decades. The orange, green, and purple bars show the frequencies of stems in the 1st, 2nd, and 3rd decade, respectively.

"target" [109], and "regulatori" [110] were found in the ranking. In terms of the corresponding experimental methods, some new techniques including digital droplet PCR (ddPCR) [111], whole-genome screen [112], and multiplexed fluorescent microsphere-based immunoassay (xMAP technology) [113] were widely adopted. Besides, a new type of cell was found in the list, dendritic cells [26], as one of the sentinel cells. Dendritic cells are the most important and primary antigen-presenting cells of asthma. They take up the antigen, process it, and present the processed antigen to T cells [114]. Therefore, dendritic cellrelated studies may be one of the breakthroughs in the treatment of asthma.

\section{Conclusion and Future Trends}

The number of cell research studies of asthma indexed by MEDLINE has increased rapidly. According to the ranking list of frequent stems, scholars paid more attention to experimental research, especially mechanistic research, rather than clinical research. The immunocyte studies and structural cell research are the two main directions. Eosinophils, mast cells, and $\mathrm{T}$ cells are the hot spots of immunocyte studies, while epithelia and SMCs are the hot spots of structural cell research. The research trend is closely linked with the development of experimental technology, including animal models. Early studies featured basic research, but immunity research has dominated in the recent decade with the development of genetic technology.

Based on the stem rankings of three decades, future trends can be predicted in the following aspects: (1) The distinct definition of asthma phenotypes associated with genetic characteristics will provide benefits for basic studies and clinical therapy. For instance, personalized medicine treatment tailored to individual's asthma phenotypes identified through biomarkers [115]. (2) Immunity research involving signaling pathways, regulatory mechanisms, targets with specific biomarkers, and so on at the gene level will provide more evidence for the pathogenesis of asthma. Meanwhile, the discovery of asthma biomarkers will contribute to characterize the population and associate the disease with environmental and therapeutic effects [116], as well as predict prognosis [117]. (3) The study of new cells regulating allergy, inflammation, or remodeling of airways, such as dendritic cells, type 2 innate lymphoid cells [118], and regulatory $\mathrm{T}$ cells [119], will bring the potential to provide therapeutic benefits.

\section{Conflicts of Interest}

The authors declare no conflicts of interest regarding the publication of this paper.

\section{Authors' Contributions}

Yi Shang and Wenchao Tang developed and designed the study. Wenchao Tang performed the programming. Wenchao Tang wrote the paper. Bin Xiao, Peitong Wen, Ruoyun Lyu, and Ke Ning reviewed and edited the manuscript. All authors read and approved the manuscript.

\section{Acknowledgments}

This work was supported by National Natural Science Foundation of China (Grant no. 81403469). 


\section{References}

[1] K. Raemdonck, K. Baker, N. Dale et al., "CD4(+) and CD8(+) $T$ cells play a central role in a HDM driven model of allergic asthma," Respiratory Research, vol. 17, no. 1, p. 45, 2016.

[2] J. P. Lynch, M. A. Ferreira, and S. Phipps, "Th2/Th17 reciprocal regulation: twists and turns in the complexity of asthma phenotypes," Annals of Translational Medicine, vol. 4, no. S1, p. S59, 2016.

[3] S. Koch, N. Sopel, and S. Finotto, "Th9 and other IL-9producing cells in allergic asthma," Seminars in Immunopathology, vol. 39, no. 1, pp. 55-68, 2017.

[4] S. Suzuki, M. Ogawa, S. Ohta et al., "Induction of airway allergic inflammation by hypothiocyanite via epithelial cells," Journal of Biological Chemistry, vol. 291, no. 53, pp. 2721927227, 2016.

[5] Q. M. Pei, P. Jiang, M. Yang et al., "Upregulation of a disintegrin and metalloproteinase-33 by VEGF in human airway smooth muscle cells: implications for asthma," Cell Cycle, vol. 15, no. 20, pp. 2819-2826, 2016.

[6] M. Schmidt and S. Mattoli, "A mouse model for evaluating the contribution of fibrocytes and myofibroblasts to airway remodeling in allergic asthma," Methods in Molecular Biology, vol. 1032, pp. 235-255, 2013.

[7] M. Mohammadian, M. H. Boskabady, I. R. Kashani et al., "Effect of bone marrow derived mesenchymal stem cells on lung pathology and inflammation in ovalbumin-induced asthma in mouse," Iranian Journal of Basic Medical Sciences, vol. 19, no. 1, pp. 55-63, 2016.

[8] A. O’Driscoll, J. Daugelaite, and R. D. Sleator, "Big data', Hadoop and cloud computing in genomics," Journal of Biomedical Informatics, vol. 46, no. 5, pp. 774-781.

[9] I. A. T. Hashem, I. Yaqoob, N. B. Anuar, S. Mokhtar, A. Gani, and S. U. Khan, "The rise of "big data" on cloud computing: review and open research issues," Information Systems, vol. 47, pp. 98-115, 2015.

[10] T. Bekhuis, M. Kreinacke, H. Spallek, M. Song, and J. A. O’Donnell, "Using natural language processing to enable in-depth analysis of clinical messages posted to an Internet mailing list: a feasibility study," Journal of Medical Internet Research, vol. 13, no. 4, p. e98, 2011.

[11] H. J. Jiang, C. A. Russo, and M. L. Barrett, Nationwide Frequency and Costs of Potentially Preventable Hospitalizations, 2006: Statistical Brief \#72, Healthcare Cost and Utilization Project (HCUP) Statistical Briefs, Rockville, MD, USA, 2006.

[12] I. M. de Kleer, M. Kool, M. J. de Bruijn et al., "Perinatal activation of the interleukin-33 pathway promotes type 2 immunity in the developing lung," Immunity, vol. 45, no. 6, pp. 1285-1298, 2016.

[13] J. Meng, X. Xin, Z. Liu et al., "Propofol inhibits T-helper cell type-2 differentiation by inducing apoptosis via activating gamma-aminobutyric acid receptor," Journal of Surgical Research, vol. 206, no. 2, pp. 442-450, 2016.

[14] S. U. Naveed, D. Clements, D. J. Jackson et al., "MMP-1 activation contributes to airway smooth muscle growth and asthma severity," American Journal of Respiratory and Critical Care Medicine, vol. 195, no. 8, pp. 1000-1009, 2017.

[15] A. Kicic, P. T. Stevens, E. N. Sutanto et al., "Impaired airway epithelial cell responses from children with asthma to rhinoviral infection," Clinical \& Experimental Allergy, vol. 46, no. 11, pp. 1441-1455, 2016.
[16] J. W. Steinke and L. Borish, "Immune responses in rhinovirus-induced asthma exacerbations," Current Allergy and Asthma Reports, vol. 16, no. 11, p. 78, 2016.

[17] L. M. Lee, M. Ji, M. Sinha et al., "Determinants of divergent adaptive immune responses after airway sensitization with ligands of toll-like receptor 5 or toll-like receptor 9," PLoS One, vol. 11, no. 12, Article ID e0167693, 2016.

[18] B D. Modena, E. R. Bleecker, W. W. Busse et al., "Gene expression correlated to severe asthma characteristics reveals heterogeneous mechanisms of severe disease," American Journal of Respiratory and Critical Care Medicine, vol. 195, no. 11, pp. 1449-1463, 2017.

[19] I. Suzaki, S. Kawano, K. Komiya et al., "Inhibition of IL-13induced periostin in airway epithelium attenuates cellular protein expression of MUC5AC," Respirology, vol. 22, no. 1, pp. 93-100, 2016.

[20] J. Bigler, M. Boedigheimer, J. P. Schofield et al., "A severe asthma disease signature from gene expression profiling of peripheral blood from U-BIOPRED cohorts," American Journal of Respiratory and Critical Care Medicine, vol. 195, no. 10, pp. 1311-1320, 2017.

[21] B. J. Schmiedel, G. Seumois, D. Samaniego-Castruita et al., "17q21 asthma-risk variants switch CTCF binding and regulate IL-2 production by T cells," Nature Communications, vol. 7, p. 13426, 2016.

[22] M. Ahmadi, R. Rahbarghazi, M. R. Aslani, A. A. Shahbazfar, M. Kazemi, and R. Keyhanmanesh, "Bone marrow mesenchymal stem cells and their conditioned media could potentially ameliorate ovalbumin-induced asthmatic changes," Biomedicine \& Pharmacotherapy, vol. 85, pp. 28-40, 2017.

[23] Y. Y. Kim, I. G. Je, M. J. Kim et al., "2-Hydroxy-3methoxybenzoic acid attenuates mast cell-mediated allergic reaction in mice via modulation of the FcepsilonRI signaling pathway," Acta Pharmacologica Sinica, vol. 38, no. 1, pp. 90-99, 2016.

[24] J. Zhou, D. F. Liu, C. Liu et al., "Glucocorticoids inhibit degranulation of mast cells in allergic asthma via nongenomic mechanism," Allergy, vol. 63, no. 9, pp. 1177-1185, 2008.

[25] Y. Sun, I. Peng, J. D. Webster et al., "Inhibition of the kinase ITK in a mouse model of asthma reduces cell death and fails to inhibit the inflammatory response," Science Signaling, vol. 8, no. 405, p. ra122, 2015.

[26] J. Wang, W. Zhu, Y. Chen, Z. Lin, and S. Ma, "CD38 genemodified dendritic cells inhibit murine asthma development by increasing IL-12 production and promoting Th1 cell differentiation," Molecular Medicine Reports, vol. 14, no. 5, pp. 4374-4382, 2016.

[27] W. Y. Wan, F. Hollins, L. Haste et al., "NADPH oxidase-4 overexpression is associated with epithelial ciliary dysfunction in neutrophilic asthma," Chest, vol. 149, no. 6, pp. 1445-1459, 2016.

[28] O. D. Solberg, E. J. Ostrin, M. I. Love et al., “Airway epithelial miRNA expression is altered in asthma," American Journal of Respiratory and Critical Care Medicine, vol. 186, no. 10, pp. 965-974, 2012.

[29] J. C. Lim, F. Y. Goh, S. R. Sagineedu et al., "A semisynthetic diterpenoid lactone inhibits NF-kappaB signalling to ameliorate inflammation and airway hyperresponsiveness in a mouse asthma model," Toxicology and Applied Pharmacology, vol. 302, pp. 10-22, 2016.

[30] H. Chen, X. Xu, J. Teng et al., "CXCR4 inhibitor attenuates ovalbumin-induced airway inflammation and hyperresponsiveness by inhibiting Th17 and Tc17 cell immune 
response," Experimental and Therapeutic Medicine, vol. 11, no. 5, pp. 1865-1870, 2016.

[31] A. M. Gilfillan, S. J. Austin, and D. D. Metcalfe, "Mast cell biology: introduction and overview," Advances in Experimental Medicine and Biology, vol. 716, pp. 2-12, 2011.

[32] A. D. Kraneveld, S. Sagar, J. Garssen, and G. Folkerts, "The two faces of mast cells in food allergy and allergic asthma: the possible concept of Yin Yang," Biochimica et Biophysica Acta (BBA)-Molecular Basis of Disease, vol. 1822, no. 1, pp. 93-99, 2012.

[33] G. U. Hong, B. S. Park, J. W. Park, S. Y. Kim, and J. Y. Ro, "IgE production in CD40/CD40L cross-talk of B and mast cells and mediator release via TGase 2 in mouse allergic asthma," Cellular Signalling, vol. 25, no. 6, pp. 1514-1525, 2013.

[34] G. U. Hong, J. Y. Lim, N. G. Kim, J. H. Shin, and J. Y. Ro, "IgE and IgA produced by OX40-OX40L or CD40-CD40L interaction in B cells-mast cells re-activate FcepsilonRI or FcalphaRI on mast cells in mouse allergic asthma," European Journal of Pharmacology, vol. 754, pp. 199-210, 2015.

[35] G. U. Hong, N. G. Kim, T. J. Kim, and J. Y. Ro, "CD1d expressed in mast cell surface enhances IgE production in $\mathrm{B}$ cells by up-regulating CD40L expression and mediator release in allergic asthma in mice," Cellular Signalling, vol. 26, no. 5, pp. 1105-1117, 2014.

[36] D. Kaur, E. Gomez, C. Doe et al., "IL-33 drives airway hyperresponsiveness through IL-13-mediated mast cell: airway smooth muscle crosstalk," Allergy, vol. 70, no. 5, pp. 556-567, 2015.

[37] I. D. Pavord, "Eosinophilic phenotypes of airway disease," Annals of the American Thoracic Society, vol. 10, pp. S143S149, 2013.

[38] P. Haldar, C. E. Brightling, B. Hargadon et al., "Mepolizumab and exacerbations of refractory eosinophilic asthma," New England Journal of Medicine, vol. 360, no. 10, pp. 973-984, 2009.

[39] H. G. Ortega, S. W. Yancey, B. Mayer et al., "Severe eosinophilic asthma treated with mepolizumab stratified by baseline eosinophil thresholds: a secondary analysis of the DREAM and MENSA studies," The Lancet Respiratory Medicine, vol. 4, no. 7, pp. 549-556, 2016.

[40] D. S. Robinson, "Mepolizumab treatment for asthma," Expert Opinion on Biological Therapy, vol. 13, no. 2, pp. 295302, 2012.

[41] A. H. Nissim Ben Efraim and F. Levi-Schaffer, "Tissue remodeling and angiogenesis in asthma: the role of the eosinophil," Therapeutic Advances in Respiratory Disease, vol. 2, no. 3, pp. 163-171, 2008.

[42] S. Shimizu, H. Kouzaki, T. Ogawa, K. Takezawa, I. Tojima, and T. Shimizu, "Eosinophil-epithelial cell interactions stimulate the production of MUC5AC mucin and profibrotic cytokines involved in airway tissue remodeling," American Journal of Rhinology \& Allergy, vol. 28, no. 2, pp. 103-109, 2014.

[43] H. Inoue, I. Ito, A. Niimi et al., "CT-assessed large airway involvement and lung function decline in eosinophilic asthma: The association between induced sputum eosinophil differential counts and airway remodeling," Journal of Asthma, vol. 53, no. 9, pp. 914-921, 2016.

[44] C. K. Kim, J. Choi, Z. Callaway, K. Iijima, G. Volcheck, and H. Kita, "Increases in airway eosinophilia and a th1 cytokine during the chronic asymptomatic phase of asthma," Respiratory Medicine, vol. 104, no. 10, pp. 1436-1443, 2010.
[45] K. H. Shalaby and J. G. Martin, "Overview of asthma; the place of the Tcell," Current Opinion in Pharmacology, vol. 10, no. 3, pp. 218-225, 2010.

[46] D. S. Robinson, "The role of the T cell in asthma," Journal of Allergy and Clinical Immunology, vol. 126, no. 6, pp. 10811091, 2010.

[47] D. M. Youssef, R. M. Elbehidy, D. M. Shokry, and E. M. Elbehidy, "The influence of leptin on Th1/Th2 balance in obese children with asthma," Jornal Brasileiro de Pneumologia, vol. 39, no. 5, pp. 562-568, 2013.

[48] Y. Kim, S. Lee, Y. S. Kim et al., "Regulation of Th1/Th2 cells in asthma development: a mathematical model," Mathematical Biosciences and Engineering, vol. 10, no. 4, pp. 1095-1133, 2013.

[49] Q. Wu, Y. Tang, X. Hu et al., "Regulation of Th1/Th2 balance through OX40/OX40L signalling by glycyrrhizic acid in a murine model of asthma," Respirology, vol. 21, no. 1, pp. 102-111, 2015.

[50] J. Wang, J. Wu, L. Kong et al., "BuShenYiQi formula strengthens Th1 response and suppresses Th2-Th17 responses in RSV-induced asthma exacerbated mice," Journal of Ethnopharmacology, vol. 154, no. 1, pp. 131-147, 2014.

[51] P. Wang, D. You, J. Saravia, H. Shen, and S. A. Cormier, "Maternal exposure to combustion generated PM inhibits pulmonary Th1 maturation and concomitantly enhances postnatal asthma development in offspring," Particle and Fibre Toxicology, vol. 10, no. 1, p. 29, 2013.

[52] H. Oda, T. Kawayama, H. Imaoka et al., "Interleukin-18 expression, CD8(+) T cells, and eosinophils in lungs of nonsmokers with fatal asthma," Annals of Allergy, Asthma \& Immunology, vol. 112, no. 1, pp. 23.e1-28 e1, 2014.

[53] A. J. Ravensberg, A. M. Slats, S. van Wetering et al., "CD8(+) T cells characterize early smoking-related airway pathology in patients with asthma," Respiratory Medicine, vol. 107, no. 7, pp. 959-966, 2013.

[54] C. Ito, K. Okuyama-Dobashi, T. Miyasaka et al., "CD8+ T cells mediate female-dominant IL-4 production and airway inflammation in allergic asthma," PLoS One, vol. 10, no. 10, Article ID e0140808, 2015.

[55] X. Ma, Z. A. Liang, H. Mao, Y. Liu, and M. Y. Wang, “The expression of CD25 and FOXP3 in mouse asthma and the effect of dexamethasone," Sichuan Da Xue Xue Bao Yi Xue Ban, vol. 41, no. 6, pp. 955-959, 2010.

[56] K. Botturi, Y. Lacoeuille, A. Cavailles, D. Vervloet, and A. Magnan, "Differences in allergen-induced T cell activation between allergic asthma and rhinitis: role of CD28, ICOS and CTLA-4," Respiratory Research, vol. 12, no. 1, p. 25, 2011.

[57] M. Eusebio, L. Kraszula, M. Kupczyk, P. Kuna, and M. Pietruczuk, "The effects of interleukin-10 or TGF-beta on anti-CD3/CD28 induced activation of CD8+CD28- and CD 8 $+\mathrm{CD} 28+\mathrm{T}$ cells in allergic asthma," Journal of Biological Regulators and Homeostatic Agents, vol. 27, no. 3, pp. 681692, 2013.

[58] S. Bazan-Socha, J. Zuk, B. Jakiela, G. Pulka, K. Pelka, and J. Musial, "Increased expression of alpha(2) (CD49b), alpha (4) (CD49d) and beta(1) (CD29) integrin subunits on peripheral blood $\mathrm{T}$ lymphocytes in clinically stable mild-tomoderate persistent asthma," Polish Archives of Internal Medicine, vol. 122, no. 12, pp. 585-590, 2012.

[59] A. Todo-Bom, A. Mota-Pinto, V. Alves, and M. Santos-Rosa, "Aging and asthma - changes in CD45RA, CD29 and CD95 T cells subsets," Allergologia et Immunopathologia, vol. 40, no. 1, pp. 14-19, 2012. 
[60] P. Li, Y. Gao, J. Cao et al., "CD39+ regulatory T cells attenuate allergic airway inflammation," Clinical \& Experimental Allergy, vol. 45, no. 6, pp. 1126-1137, 2015.

[61] L. L. Wang, P. H. Tang, C. G. Shi et al., "Expression of CD39 mRNA is altered in the peripheral blood of patients with allergic asthma," Biomedical Reports, vol. 2, no. 1, pp. 75-78, 2013.

[62] L. L. Wang, H. P. Tang, G. C. Shi et al., "CD39/CD73 and the imbalance of Th17 cells and regulatory $\mathrm{T}$ cells in allergic asthma," Molecular Medicine Reports, vol. 8, no. 5, pp. 1432-1438, 2013.

[63] E. H. Mann, E. S. Chambers, Y. H. Chen, D. F. Richards, and C. M. Hawrylowicz, "1alpha,25-dihydroxyvitamin D3 acts via transforming growth factor-beta to up-regulate expression of immunosuppressive CD73 on human CD4+ Foxp3T cells," Immunology, vol. 146, no. 3, pp. 423-431, 2015.

[64] N. F. Ji, Y. C. Xie, M. S. Zhang et al., "Ligustrazine corrects Th1/Th2 and Treg/Th17 imbalance in a mouse asthma model," International Immunopharmacology, vol. 21, no. 1, pp. 76-81, 2014.

[65] L. Fan, X. Wang, L. Fan et al., "MicroRNA-145 influences the balance of Th1/Th2 via regulating RUNX3 in asthma patients," Experimental Lung Research, vol. 42, no. 8-10, pp. 417-424, 2016.

[66] J. Wang, R. G. Jin, L. Xiao, Q. J. Wang, and T. H. Yan, “Antiasthma effects of synthetic salidroside through regulation of Th1/Th2 balance," Chinese Journal of Natural Medicines, vol. 12, no. 7, pp. 500-504, 2014.

[67] M. Zhu, Z. Liang, T. Wang, R. Chen, G. Wang, and Y. Ji, "Th1/Th2/Th17 cells imbalance in patients with asthma with and without psychological symptoms," Allergy and Asthma Proceedings, vol. 37, no. 2, pp. 148-156, 2016.

[68] S. G. Royce, K. P. Patel, and C. S. Samuel, "Characterization of a novel model incorporating airway epithelial damage and related fibrosis to the pathogenesis of asthma," Laboratory Investigation, vol. 94, no. 12, pp. 1326-1339, 2014.

[69] K. McLellan, M. Shields, U. Power, and S. Turner, "Primary airway epithelial cell culture and asthma in children-lessons learnt and yet to come," Pediatric Pulmonology, vol. 50, no. 12, pp. 1393-1405, 2015.

[70] I. H. Heijink, M. C. Nawijn, and T. L. Hackett, "Airway epithelial barrier function regulates the pathogenesis of allergic asthma," Clinical \& Experimental Allergy, vol. 44, no. 5, pp. 620-630, 2014.

[71] D. A. Patel, Y. You, G. Huang et al., "Interferon response and respiratory virus control are preserved in bronchial epithelial cells in asthma," Journal of Allergy and Clinical Immunology, vol. 134, no. 6, pp. 1402.e7-1412 e7, 2014.

[72] A. L. Tatler, A. E. John, L. Jolly et al., "Integrin alphavbeta5mediated TGF-beta activation by airway smooth muscle cells in asthma," Journal of Immunology, vol. 187, no. 11, pp. 6094-6107, 2011.

[73] P. Borger, N. Miglino, M. Baraket, J. L. Black, M. Tamm, and M. Roth, "Impaired translation of CCAAT/enhancer binding protein alpha mRNA in bronchial smooth muscle cells of asthmatic patients," Journal of Allergy and Clinical Immunology, vol. 123, no. 3, pp. 639-645, 2009.

[74] H. Alkhouri, F. Hollins, L. M. Moir, C. E. Brightling, C. L. Armour, and J. M. Hughes, "Human lung mast cells modulate the functions of airway smooth muscle cells in asthma," Allergy, vol. 66, no. 9, pp. 1231-1241, 2011.

[75] J. Pekkanen, J. Lampi, J. Genuneit, A. L. Hartikainen, and M. R. Jarvelin, "Analyzing atopic and non-atopic asthma,"
European Journal of Epidemiology, vol. 27, no. 4, pp. 281-286, 2012.

[76] A. C. Jirmo, K. Daluege, C. Happle et al., "IL-27 is essential for suppression of experimental allergic asthma by the TLR7/ 8 Agonist R848 (Resiquimod)," Journal of Immunology, vol. 197, no. 11, pp. 4219-4227, 2016.

[77] S. S. Athari, S. M. Athari, F. Beyzay, M. Movassaghi, E. Mortaz, and M. Taghavi, "Critical role of Toll-like receptors in pathophysiology of allergic asthma," European Journal of Pharmacology, vol. 808, pp. 21-27, 2017.

[78] P. Fang, H. Y. Shi, X. M. Wu et al., "Targeted inhibition of GATA- 6 attenuates airway inflammation and remodeling by regulating caveolin-1 through TLR2/MyD88/NF-kappaB in murine model of asthma," Molecular Immunology, vol. 75, pp. 144-150, 2016.

[79] M. E. Ferrini, S. Hong, A. Stierle et al., "CB2 receptors regulate natural killer cells that limit allergic airway inflammation in a murine model of asthma," Allergy, vol. 72, no. 6, pp. 937-947, 2017.

[80] X. Diao, J. Wang, H. Zhu, and B. He, "Overexpression of programmed cell death 5 in a mouse model of ovalbumininduced allergic asthma," BMC Pulmonary Medicine, vol. 16, no. 1, p. 149, 2016.

[81] X. Y. Zhang, L. J. Ma, Y. L. Guo et al., "Effect of BCYRN1 on proliferation and migration of airway smooth muscle cells in rat model of asthma," Zhonghua Yi Xue Za Zhi, vol. 96, no. 46, pp. 3751-3756, 2016.

[82] C. Tabeling, J. Herbert, A. C. Hocke et al., "Spleen tyrosine kinase inhibition blocks airway constriction and protects from Th2-induced airway inflammation and remodeling," Allergy, vol. 72, no. 7, pp. 1061-1072, 2017.

[83] H. Nakajima and K. Takatsu, "Role of cytokines in allergic airway inflammation," International Archives of Allergy and Immunology, vol. 142, no. 4, pp. 265-273, 2007.

[84] W. W. Busse and J. N. Gaddy, "The role of leukotriene antagonists and inhibitors in the treatment of airway disease," American Review of Respiratory Disease, vol. 143, no. 5, pp. S103-S107, 1991

[85] H. Z. Shi, S. Li, Z. F. Xie, X. J. Qin, X. Qin, and X. N. Zhong, "Regulatory CD4+CD25+ T lymphocytes in peripheral blood from patients with atopic asthma," Clinical Immunology, vol. 113, no. 2, pp. 172-178, 2004.

[86] C. Duez, P. Gosset, and A. B. Tonnel, "Dendritic cells and toll-like receptors in allergy and asthma," European Journal of Dermatology, vol. 16, no. 1, pp. 12-16, 2006.

[87] S. Kai, A. Nomura, Y. Morishima et al., "Effect of inhaled steroids on increased collagen synthesis in asthma," Respiration, vol. 74, no. 2, pp. 154-158, 2006.

[88] K. Karwat, M. Kumor, and R. Chazan, "Coagulation parameters associated with inhaled glucocorticosteroid therapy in stable asthma," Polski Merkuriusz Lekarski, vol. 18, no. 107, pp. 527-529, 2005.

[89] K. Massingham, S. Fox, and A. Smaldone, "Asthma therapy in pediatric patients: a systematic review of treatment with montelukast versus inhaled corticosteroids," Journal of Pediatric Health Care, vol. 28, no. 1, pp. 51-62, 2014.

[90] M. C. Catley, J. Coote, M. Bari, and K. L. Tomlinson, "Monoclonal antibodies for the treatment of asthma," Pharmacology \& Therapeutics, vol. 132, no. 3, pp. 333-351, 2011.

[91] S. Toki, K. Goleniewska, S. Reiss et al., "The histone deacetylase inhibitor trichostatin A suppresses murine innate allergic inflammation by blocking group 2 innate 
lymphoid cell (ILC2) activation,” Thorax, vol. 71, no. 7, pp. 633-645, 2016.

[92] J. Choi, B. K. Choi, J. S. Kim et al., "Picroside II attenuates airway inflammation by downregulating the transcription factor GATA3 and Th2-related cytokines in a mouse model of HDM-induced allergic asthma," PLoS One, vol. 12, no. 1, Article ID e0167098, 2017.

[93] A. L. da Silva, R. F. Magalhaes, V. C. Branco et al., "The tyrosine kinase inhibitor dasatinib reduces lung inflammation and remodelling in experimental allergic asthma," British Journal of Pharmacology, vol. 173, no. 7, pp. 1236-1247, 2016.

[94] P. Norman, "Inducible tyrosine kinase inhibitors: a review of the patent literature (2010-2013)," Expert Opinion on Therapeutic Patents, vol. 24, no. 9, pp. 979-991, 2014.

[95] Z. L. Lummus, R. Alam, J. A. Bernstein, and D. I. Bernstein, "Characterization of histamine releasing factors in diisocyanate-induced occupational asthma," Toxicology, vol. 111, no. 1-3, pp. 191-206, 1996.

[96] I. A. Shiels, S. D. Bowler, and S. M. Taylor, "Homologous serum increases fibronectin expression and cell adhesion in airway smooth muscle cells," Inflammation, vol. 20, no. 4, pp. 373-387, 1996.

[97] T. Sano, Y. Nakamura, Y. Matsunaga et al., "FK506 and cyclosporin A inhibit granulocyte/macrophage colonystimulating factor production by mononuclear cells in asthma," The European Respiratory, vol. 8, no. 9, pp. 14731478, 1995.

[98] B. Wallaert, P. Desreumaux, M. C. Copin et al., "Immunoreactivity for interleukin 3 and 5 and granulocyte/ macrophage colony-stimulating factor of intestinal mucosa in bronchial asthma," Journal of Experimental Medicine, vol. 182, no. 6, pp. 1897-1904, 1995.

[99] C. Walker, E. Bode, L. Boer, T. T. Hansel, K. Blaser, and J. C. Virchow Jr., "Allergic and nonallergic asthmatics have distinct patterns of T-cell activation and cytokine production in peripheral blood and bronchoalveolar lavage," American Review of Respiratory Disease, vol. 146, no. 1, pp. 109-115, 1992.

[100] Y. Tanizaki, H. Kitani, M. Okazaki et al., "Changes in bronchoalveolar cell profiles of asthma patients induced by long-term glucocorticoid therapy," Nihon Kyobu Shikkan Gakkai Zasshi, vol. 31, no. 6, pp. 717-724, 1993.

[101] E. W. Alton and A. A. Norris, "Chloride transport and the actions of nedocromil sodium and cromolyn sodium in asthma," Journal of Allergy and Clinical Immunology, vol. 98, no. 5, pp. S102-S105, 1996.

[102] L. F. Zhou, Y. Zhu, X. F. Cui, W. P. Xie, A. H. Hu, and K. S. Yin, "Arsenic trioxide, a potent inhibitor of NF-kappaB, abrogates allergen-induced airway hyperresponsiveness and inflammation," Respiratory Research, vol. 7, no. 1, 146 pages, 2006.

[103] P. W. Hellings, A. Kasran, D. Bullens et al., "IL-10- and IL12-independent down-regulation of allergic sensitization by stimulation of CD40 signaling," Journal of Immunology, vol. 177, no. 8, pp. 5138-5144, 2006.

[104] M. J. Leckie, A. ten Brinke, J. Khan et al., "Effects of an interleukin-5 blocking monoclonal antibody on eosinophils, airway hyper-responsiveness, and the late asthmatic response," The Lancet, vol. 356, no. 9248, pp. 2144-2148, 2000.

[105] Y. L. Tang, C. P. Hu, J. T. Feng, J. Q. Zhu, and M. J. Lin, "Regulation effect of nerve growth factor on Ras-MAPK signal transduction pathway in neurogenic inflammation of asthma," Zhong Nan Da Xue Xue Bao Yi Xue Ban, vol. 31, no. 3, pp. 319-325, 2006.

[106] W. Duan and W. S. Wong, "Targeting mitogen-activated protein kinases for asthma," Current Drug Targets, vol. 7, no. 6, pp. 691-698, 2006.

[107] D. Kaur, R. Saunders, P. Berger et al., "Airway smooth muscle and mast cell-derived CC chemokine ligand 19 mediate airway smooth muscle migration in asthma," American Journal of Respiratory and Critical Care Medicine, vol. 174, no. 11, pp. 1179-1188, 2006.

[108] Z. Wang, H. Zhang, X. Sun, and L. Ren, "The protective role of vitamin D3 in a murine model of asthma via the suppression of TGF-beta/Smad signaling and activation of the Nrf2/HO-1 pathway," Molecular Medicine Reports, vol. 14, no. 3, pp. 2389-2396, 2016.

[109] R. Zhang, H. Dong, H. Zhao, L. Zhou, F. Zou, and S. Cai, "1,25-Dihydroxyvitamin D3 targeting VEGF pathway alleviates house dust mite (HDM)-induced airway epithelial barrier dysfunction," Cellular Immunology, vol. 312, pp. 15-24, 2017.

[110] C. Martins, J. Lima, G. Nunes, and L. M. Borrego, "Regulatory $\mathrm{T}$ and $\mathrm{B}$ cells in asthmatic women: variations from pregnancy to postpartum Treg and Breg: pregnancy to postpartum," Journal of Investigational Allergology and Clinical Immunology, vol. 27, no. 1, 2017.

[111] M. Sze, Y. Oh, S. J. Yang et al., “A32 MICROBIAL INTERACTIONS AND HOST DEFENSE: The bacterial microbiome of gut, lung, and blood after H1n1 influenza virus infection in mice with and without house dust mite exposure," American Journal of Respiratory and Critical Care Medicine, vol. 191, no. 1, 2015.

[112] C. D. Campbell, K. Mohajeri, M. Malig et al., "Wholegenome sequencing of individuals from a founder population identifies candidate genes for asthma," PLoS One, vol. 9, no. 8, Article ID e104396, 2014.

[113] A. Panariti, V. Narayanan, C. Baglole et al., "Increased vascularity of the bronchial mucosa in patients with severe asthma and the role of IL-17A in angiogenesis and vascular remodeling," in Proceeding of D31 Novel Mechanisms of Allergy and Airway Inflammation, p. A6680, American Thoracic Society, New York, NY, USA, 2016.

[114] A. S. Bharadwaj, A. K. Bewtra, and D. K. Agrawal, "Dendritic cells in allergic airway inflammation," Canadian Journal of Physiology and Pharmacology, vol. 85, no. 7, pp. 686-699, 2007.

[115] M. Godar, C. Blanchetot, H. de Haard, B. N. Lambrecht, and G. Brusselle, "Personalized medicine with biologics for severe type 2 asthma: current status and future prospects," MAbs, vol. 10, no. 1, pp. 34-45, 2017.

[116] I. Agache and L. Rogozea, "Asthma biomarkers: do they bring precision medicine closer to the clinic?," Allergy, Asthma \& Immunology Research, vol. 9, no. 6, pp. 466-476, 2017.

[117] B. S. Berthon, P. G. Gibson, L. G. Wood, L. K. MacDonaldWicks, and K. J. Baines, "A sputum gene expression signature predicts oral corticosteroid response in asthma," European Respiratory Journal, vol. 49, no. 6, article 1700180, 2017.

[118] L. Cosmi, F. Liotta, L. Maggi, and F. Annunziato, "Role of type 2 innate lymphoid cells in allergic diseases," Current Allergy and Asthma Reports, vol. 17, no. 10, p. 66, 2017.

[119] L. Bohm, J. Maxeiner, H. Meyer-Martin et al., "IL-10 and regulatory $\mathrm{T}$ cells cooperate in allergen-specific immunotherapy to ameliorate allergic asthma," Journal of Immunology, vol. 194, no. 3, pp. 887-897, 2017. 


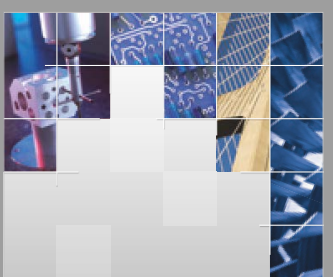

\section{Enfincering}
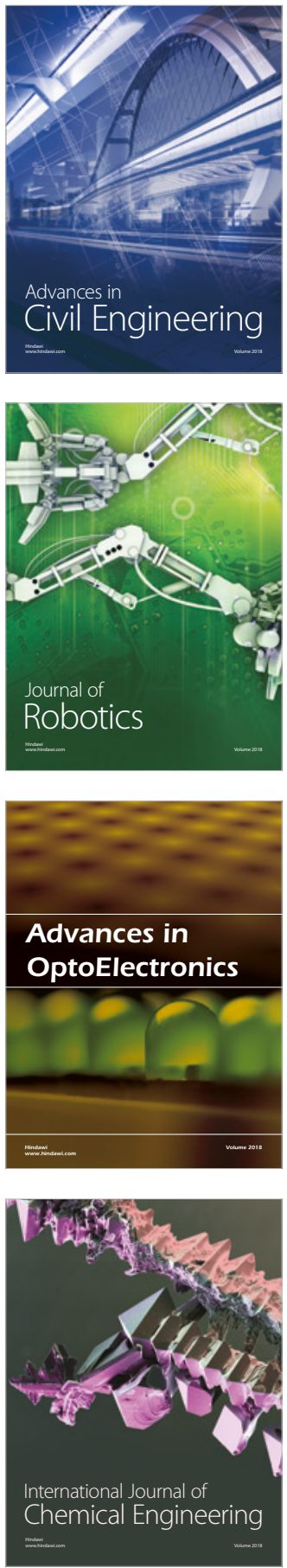

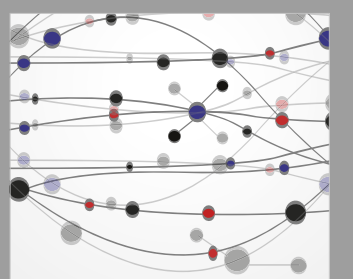

\section{Rotating \\ Machinery}

The Scientific World Journal

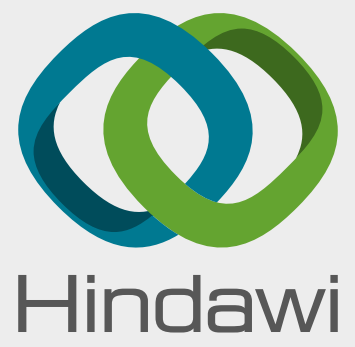

Submit your manuscripts at

www.hindawi.com
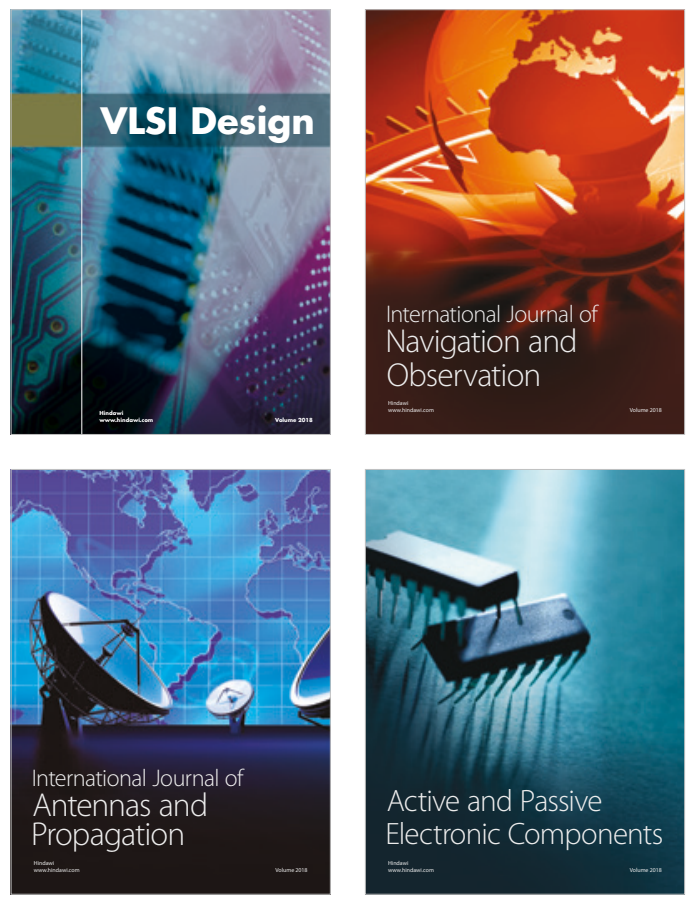
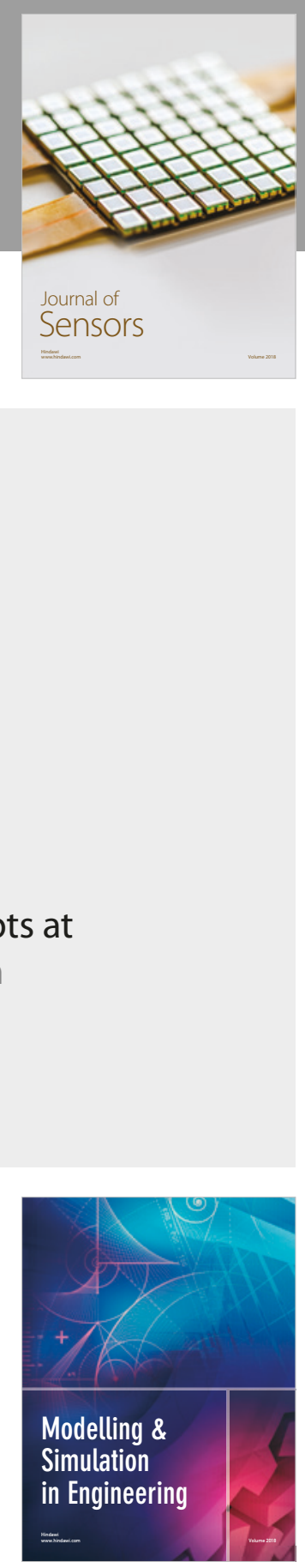

\section{Advances \\ Multimedia}
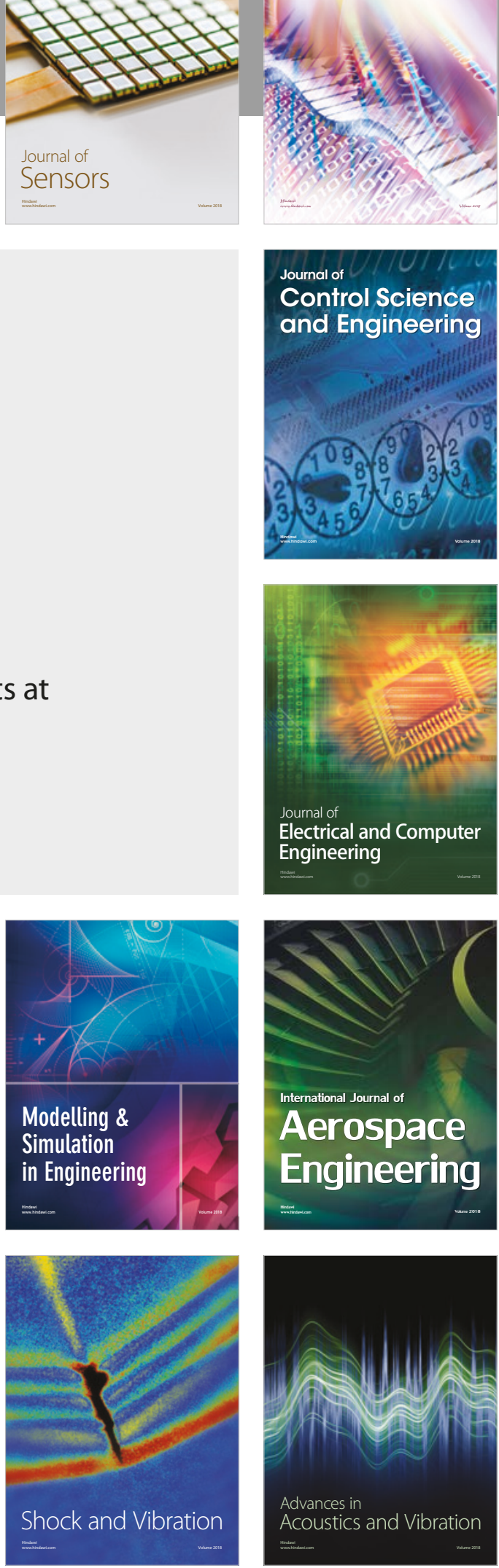